\title{
Research on the Management of Digital Photo Archives in Colleges and Universities
}

\author{
Ying Zhang \\ Jilin Agricultural University archives \\ 474269500@qq.com
}

Keywords: University; Digital photo; Countermeasures

\begin{abstract}
Currently, a large number of electronic equipment like digital camera, mobile phone and others are widely used in teaching and research in universities, so it is natural to form some digital photos which have become the certificate for the university development, materials and information publicity as an important means of communication. However, generally speaking, the management of digital photos is not standardized. This paper firstly analyzes the current situations of digital photo management, their existing problems and the necessity of solution. On the basis, the countermeasures and methods of collection of digital photos are put forward.
\end{abstract}

\section{Introduction}

Digital photo archives of colleges and universities refers to the various departments, organizations or individuals in school activities through the digital camera, mobile phone and other electronic products direct shooting digital image as the main reflection of history has kept the value of the. Because of the vivid image, easy to copy, transmission and other characteristics, has been used as the main promotional materials and means of communication in university teaching and research activities. But how about the massive digital photos for screening, sorting, archiving and storage, the traditional photos and digital photos organically, standardized and scientific management, has become a new topic that we urgently need to solve.

\section{The Causes and Effects of Current Management of Digital Photo Files}

The Management System is not perfect. Digital photos in recent years is the emergence of new things, so the digital photo file management system is not perfect enough, the relevant provisions are lagging behind. So far, the file did not form a widely recognized digital photo archives management measures, although the national archives have been issued in 2002 "photo archives management standards" and other related policy documents, but not the standard management involved in the digital photo file specific standard case management; although some regulations in the digital photo as a kind of audio and video files, but did not establish a separate filing system. [1]There is no guarantee of the system, the digital photo archive has no foundation, but also directly affects the management of digital photo archives.

The Collection is Difficult, Showing Serious Leakage. The universal application of digital cameras, the various departments of the school can take pictures of the activities of the unit, a large number of digital photos of the long-term dispersion in the unit or personal computer, resulting in a wide range of collection, difficulty.[2] From the actual situation of the school, because the primary sector part-time archivists most without archival professional training, and thought hard enough, not timely filing of digital photo archives consciousness, resulting in digital photo formation, not timely return trochees, seriously affected the normal development of digital photo file collection work. In addition, there is no clear division of responsibility for the photographer and manager of digital photos, frequent changes in personnel also caused some digital photos of the loss resulting in the phenomenon of leakage. 
Sorting is not Timely and Standardized, Causing the Preservation of Hysteresis. Digital photos without negatives, easy to use, digital photo shoot in the finished task, most of the large quantities of digital photos turn stored in the computer, if no special requirements or special circumstances; generally do not take the initiative to organize digital photos. Over time, more and more photo files stored in the computer, finishing procedures more complex; on the other hand, the digital photo archive was handed over after the photos and a large amount of manpower shortage, caused by the consolidation of heavy workload, the work can not be completed timely digital photos. Because there is no uniform rules and standards, digital photo management text description, how to classify, numbering, etc. there is no uniform provisions, which will bring a lot of difficulties filing digital photo files.

Digital Photos Lack of Security Management. Recently, the general office of the CPC Central Committee and the general office of the State Council on strengthening and improving the work of the archives under the new situation, it is proposed to establish a sound file security system to ensure the security and confidentiality of archives.[3] Digital photos due to the formation of more randomness, the source is not affected by monitoring, first of all, personal photos in the mobile phone, camera and computer to browse, copy, use easily damaged, even leak secret. Secondly, the photos in the local area network of more than one computer or web site work in conjunction with each other, through the slide projector, recorder, printer and other equipment connected to the transfer, there are many unsafe factors. Moreover, in recent years, the computer virus caused by the electronic file damage or loss is also common, which are threatening the security of digital photos. .

\section{The Necessity of Solving the Problem}

The Role of Digital Photos. Digital photo archives of university records of the school construction, teaching reform, teacher style and other major events, the staff understand the true appearance and development process of the school through the digital photo archives, photo archives and all kinds of paper files in the content of each other, complement each other in form, with a strong memory and display of historical function.[4] With the development of the information society and the wide application of the network technology, more and more digital photo archives play its unique function in the school development, good photo archives management work, give full play to the photo archives memory and representation of history features, is of great significance.

The Significance of Digital Photos. The standard of University Digital Photo significance is conducive to the maintenance of the system, the authenticity of digital photo archives, is conducive to the digital photos of the exchange of information, sharing of resources, but also lay a solid foundation for the realization of Archives standardization and modernization management. The ultimate goal is to provide archival materials filed by then, digital photos due to the particularity of its own, it also determines the ease of use, the archives staff can find full-text search pictures by scanning the database, according to the need to print the selected photos, users can see the search to a small image, logo and title and other information, greatly improving the utilization rate and efficiency. In addition, due to the fact that many departments do not have a special digital photo retrieval system, the difficulty of digital photo retrieval is serious, which makes it difficult to develop and utilize digital photo archive resources effectively. How to strengthen the standardization of digital photo archives management in Colleges and universities.

\section{Digital Photo Collection Strategies and Methods}

The collection of digital photos should not only learn from the traditional methods of collecting photos, but also develop a set of effective collection and management methods according to the current characteristics and development trend of digital photography.

Strengthen Leadership's Attention and the Implementation of the System. The unit leadership attention is the key factor to clear the main leadership to be responsible for the work of 
archives, archives, establish and improve the corresponding management institutions, unified management of the unit formed in the work in the archives, carefully organize the relevant departments to digital photo shooting, collecting, archiving, storage, borrowing, use and other aspects, develop a set of practical "digital photo archives management measures", rationalize the relationship between archives management and the production department, the Department of archives in the digital photo archive management laws and rules to follow, to prevent the system from the current file management loopholes.

Designated Person Responsible for the Collection, Identification and Archiving of Digital Photo Files. The archives management department shall designate the person responsible for the collection, sorting and classification of digital photo archives. In order to make the digital photo file manager's job responsibilities to be implemented, should put forward the specific requirements of the photo collection content, clear the scope of archiving, archiving process. Specialized in the production of photo album, so that each photo has a note, including time, place, content, the main characters and photographers.[5] Active organizer of part-time archivist at the end of the unit by time, should be timely collect photos sorting system, the finished shooting digital photos with text background, unified filing to the archives department.

Only the responsibility to the people, the work requires clear, the formation of a routine is likely to effectively solve the problem due to the scattered photos stored or lost, the formation of digital photo file collection work network.

According to the Rules and Regulations, Screening Digital Photos must be Strict. The digital photos should be archived in strict accordance with the "photo file management norms", "electronic filing and management regulations Fan management. Digital photo archiving, should be based on its technical conditions for testing, including hardware environment, The validity of the software environment, record format, notes, numbers and other content is complete. Archiving of electronic file format is JPG or TIFF format, the resolution is to meet the requirements, whether the image after modification, Add, synthesis and other editing process to ensure the effectiveness and authenticity of digital photos.

The Management of Digital Photos should be Scientific and Standardized. The filing of the photos to be a reasonable classification, the preparation of the file directory, including the title of the title, time, photographer, text, etc.. The description includes the basic information such as time, place, character, subject, background, etc. it is the important content of the photo and the important element of the photo.

Carrier Safekeeping, Strengthen Security Protection. To keep the archives of digital photos should be established respectively three form a CD-ROM is backup, two copies were saved offline, away from strong magnetic field; the two is the mobile hard disk, large storage capacity of hard disk, hard disk storage environment should pay attention to avoid glare, magnetization, and bump; three is the traditional paper photos. Some commonly used data should be selected and representative and value of digital photo output, a high quality paper photo finishing preservation, convenient use. The implementation needs a set of paper, two sets of electronic, and three backup systems. The $\mathrm{CD}-\mathrm{ROM}$ and hard disk may be due to dust, light, use frequency, collision and other environmental factors to reduce life expectancy, which is the traditional way of saving paper photos, as long as the preservation of the environment properly, can be preserved for a long time, in the digital image are lost, and can also use paper photos remake, scanning. The digital image needs real recovery. Digital photo archives are an important part of archival resources.

Digital photo archives need to increase the intensity of the Propaganda Department, so that all departments fully aware of the important role of digital photos to work. File management departments should effectively regulate and improve the digital photo file management system, and constantly improve the level of scientific management, so that digital photo files in the cultural education and social economic activities play a better role. 


\section{Countermeasures and Conclusion}

Increase Publicity Efforts to Improve the Sense of Archives. Archives to increase the publicity of the archives regulations, so that the school staff fully aware of the teaching, scientific research and daily management work in the digital photo file is an important witness to the development of the school, need to save. Actively take various effective measures to enhance the various departments of the archive consciousness, the use of network technology to promote the school big events, such as school construction, school evaluation, academia, expand the influence of the photo archives through various photo archives exhibition, to promote the collection work. At the same time, school leaders should give strong support to the various departments of the school should give positive cooperation. Improve the system, investment funds, adjust the structure of management personnel, making the digital photo file to give full play to the role of the service center, serving the community, fully reflect the value of the file.

Improve the Corresponding Digital Photo Collection Management System. In the process of transferring and receiving digital photos, first of all, to clear the scope of the collection and archiving process. Make the card marked special, each photo should be marked in accordance with numbers, including the shooting time, main content, location and photography, ensure each photograph is standardized and effective, so as to improve the quality and efficiency. Part-time archivists will input to the electronic version of the photo archives management in iron according to uniform standards, such as the coordination of the central school archives departments, complete the standardization of digital photo collection and filing work.

The Construction of Digital Photo Archives Standardized Database for Management. The construction of digital photo archives database in Colleges and universities, so as to meet the needs of the construction and development of digital photo archives. The archives department in the reception of digital photos, first of all to keep value on the digital photo identification, to determine the choice and storage period, should choose the photo formed in Universities in various activities have important value in the photo archive. To archive digital photo finishing, first of all, according to the annual classification form, then according to different classification; secondly, in the catalogue, compiled by one fonds number and storage period, time, photography, photo captions to clear handwriting font specification, row spacing is moderate; thirdly, engraving the CD to two copies, one for access, a preservation. Finally, the information of the digital photos that have been filed into the file management information system of the school, in order to query and use.

Strengthen the Old Photos, lost Photos Management. Can be related to major historical events, outstanding figures, the number of organizations and the full number of old photos compiled into a photo archive, the use of modern scientific and technological means of scanning and recording, made of CD-ROM. It not only protects the original photo archives, but also facilitates the use of the system. Through the dispatch, letters, visits and other means, a large number of lost historical photos collected into the museum. For example, at different times, party and state leaders chairman mao, Liu Shaoji met with the national agricultural science and technology work conference delegates and Jiang Zemin, Li Peng met with the National Party Representatives photo and other precious archives into the library, and to fill the gaps in the history of the school, to expand the space of digital photos, rich collection.

\section{References:}

[1] D. X. Dou. The Research on the Problems and Countermeasures of College Archives Arrangement under the New Environment" [J], 2016

[2] S.F. Li. Interpretation, Practice and Exploration of School Photo Archives Management [J] Electronic Archives, 2008

[3] X.W. Zhang. The Problems and Countermeasures of the Management of Digital Photo Archives in Colleges and Universities [J], Shanghai archives, 2007 
[4] F.G. Wang Standardized Management of University Digital Photo Archives [J] Journal of Liaocheng University, 2006

[5] Z.Z. Zhong. Digital Photo Archiving and Management [J]. Exam Week, 2011 